\title{
Phase-contrast and dark-field imaging for the inspection of resin-rich areas and fiber orientation in non-crimp vacuum infusion carbon-fiber- reinforced polymers
}

\author{
Jonathan Glinz ${ }^{1,2, \star}$ (D), Jan Šleichrt ${ }^{3}$, Daniel Kytýr $\check{r}^{4}$, Santhosh Ayalur-Karunakaran ${ }^{5}$, \\ Simon Zabler ${ }^{6,7}$, Johann Kastner ${ }^{2}$, and Sascha Senck ${ }^{2}$ \\ ${ }^{1}$ Institut für Werkstoffwissenschaft und Werkstofftechnologie, TU Wien, Getreidemarkt 9, 1060 Wien, Austria \\ ${ }^{2}$ Research Group Computed Tomography, University of Applied Sciences Upper Austria, Stelzhamerstraße 23, 4600 Wels, Austria \\ ${ }^{3}$ Faculty of Transportation Sciences, Czech Technical University in Prague, Konviktská 20, 11000 Prague, Czech Republic \\ ${ }^{4}$ Institute of Theoretical and Applied Mechanics, Czech Academy of Sciences, Prosecká 809/76, 19000 Prague, Czech Republic \\ ${ }^{5}$ FACC Operations GmbH, Fischerstraße 9, 4910 Ried im Innkreis, Austria \\ ${ }^{6}$ Lehrstuhl für Röntgenmikroskopie, Universität Würzburg, Josef-Martin-Weg 63, 97074 Würzburg, Germany \\ ${ }^{7}$ Magnetic Resonance and X-Ray Department, Fraunhofer EZRT, Josef-Martin-Weg 63, 97074 Würzburg, Germany
}

Received: 2 September 2020

Accepted: 4 February 2021

Published online:

22 February 2021

(C) The Author(s) 2021

\begin{abstract}
In this work, we present a multimodal approach to three-dimensionally quantify and visualize fiber orientation and resin-rich areas in carbon-fiber-reinforced polymers manufactured by vacuum infusion. Three complementary image modalities were acquired by Talbot-Lau grating interferometer (TLGI) X-ray microcomputed tomography (XCT). Compared to absorption contrast (AC), TLGI-XCT provides enhanced contrast between polymer matrix and carbon fibers at lower spatial resolutions in the form of differential phase contrast (DPC) and dark-field contrast (DFC). Consequently, relatively thin layers of resin, effectively indiscernible from image noise in AC data, are distinguishable. In addition to the assessment of fiber orientation, the combination of DPC and DFC facilitates the quantification of resin-rich areas, e.g., in gaps between fiber layers or at binder yarn collimation sites. We found that resin-rich areas between fiber layers are predominantly developed in regions characterized by a pronounced curvature. In contrast, in-layer resin-rich areas are mainly caused by the collimation of fibers by binder yarn. Furthermore, void volume around two adjacent $90^{\circ}$-oriented fiber layers is increased by roughly $20 \%$ compared to a random distribution over the whole specimen.
\end{abstract}

Handling Editor: Dale Huber.

Address correspondence to E-mail: jonathan.glinz@fh-wels.at 


\section{Introduction}

The high strength at moderate weight in combination with superior corrosion and fatigue properties [1, 2] makes carbon-fiber-reinforced polymer (CFRP) an attractive material for lightweight applications in aerospace. Nonetheless, besides several benefits, CFRP components also bear significant risks like a low resistance to impact damage [3]. Additionally, CFRP parts are often characterized by the presence of deeply enclosed porosity, resin-rich areas and deviations from the desired fiber layup. These internal features and part-to-part variations can pose a serious threat to the mechanical integrity of a component. Therefore, particularly for safety critical parts used in aviation and aerospace applications, fast and reliable non-destructive investigation methods are essential. X-ray microcomputed tomography (XCT) is a widely established method for damage detection and characterization in CFRP $[4,5]$ but also other techniques such as ultrasonic testing [6-8] and thermography $[9,10]$ have proven suitable for the detection of internal pores and defects. In contrast, the segmentation of resin-rich areas and carbon fiber bundles is more challenging as contrast between fibers and matrix material (resin) is usually insufficient using XCT. Although, at sufficiently high resolution (often less than $1 \mu \mathrm{m}^{3}$ voxel size), individual fibers can be segmented and fiber orientation can be determined $[5,11]$. However, carbon fibers are too small to be visualized at reasonable specimen dimensions, making the combined investigation with resin-rich areas inefficient, as these are typically a multitude larger in size.

The performance of CFRP laminates is predominantly determined by their internal composition of fibers and matrix material. In particular, the orientation of carbon fibers with respect to occurring stress has a major impact on service life. Depending on load direction, even minor deviations from an ideal fiber orientation can introduce shear stress to a component's matrix material, significantly weakening its mechanical strength [11]. Such deviations are for example commonly introduced by fiber waviness, and their negative effects on stiffness and strength have already been explained in various studies $[12,13]$. Additionally, the stacking sequence of fiber layers influences mechanical properties. Fuoss et al. [14] found that stacking of adjacent layers in similar orientations should be avoided. Consequently, the prediction of mechanical behavior of CFRP components largely depends on a detailed knowledge of aforementioned deviations from an intended/ideal composition. However, Barile et al. [15] reported different levels of compressive stiffness in symmetric and balanced carbon fiber composites depending on compression direction. This suggests that apart from fiber orientation, process parameters such as resin flow direction and local accumulations of resin might as well influence mechanical properties of CFRP.

Depending on the type of composite, resin-rich areas can be caused by multiple reasons, for example, by binder yarns in woven composites that are collimating carbon fibers and consequently creating regions with low fiber content [16]. Similar effects have been observed during the integration of structures significantly thicker than carbon fibers causing a distortion in the composite layup such as embedded electronics [17], optical fibers [18] or resin vasculature in self-healing CFRP [19]. The collimation of fibers or general disturbances of the composite layup and the resulting lack of fibers in those areas can furthermore lead to an entrapment of air during resin infusion creating void spaces in the composite. The resulting porosity can significantly reduce the mechanical strength of a component, e.g., inter-laminar shear strength decreases linearly by roughly $6 \%$ for every increasing percent of porosity [20]. However, resinrich areas in components manufactured by vacuum infusion also occur independently of integrated structures, predominantly in regions where fibers are strongly bent causing a compression of fibers and leaving gaps between layers that are filled with resin during the production process [21]. The major problem of these resin-rich areas is the usual mismatch in stiffness and thermal expansion/contraction in comparison with carbon fibers [21,22].

During the resin infusion process, dry fiber sheets are placed in an airtight mold and resin is infused by underpressure impregnating the carbon fibers [23]. The subsequent curing process typically involves higher temperatures followed by a cooling of the composite during which internal stress is induced $[19,21]$. In addition, most resins have low thermal stability leading to a decomposition of the matrix material during occasional lightning strikes, which can create damage hot spots in resin-rich areas [2, 24]. Previous studies also observed that resin zones from binder yarn collimation correlate with crack initiation 
sites [25-27]. For that reasons, the formation of resinrich areas and their impact on component strength is equally important to investigate.

Using Talbot-Lau grating interferometer (TLGI) X-ray microcomputed tomography (XCT), this study explores three different $X$-ray contrast mechanisms to characterize internal features and defects in vacuuminfused aerospace-grade CFRP parts. TLGI-XCT is a novel method for the investigation of CFRP and aforementioned problems that was originally developed for synchrotron facilities in 2002 [28]. Because of the high costs and subsequent low accessibility of such facilities, efforts for the transfer of the technology to laboratory computed tomography devices were made. By use of an additional source grating, the obstacle of insufficient spatial coherence of typical laboratory X-ray systems was successfully overcome $[29,30]$ which opened TLGI-XCT for a wider range of applications. In addition to standard absorption contrast (AC), TLGI-XCT provides two complementary, simultaneously measured and mutually aligned imaging modalities, differential phase contrast (DPC) and dark-field contrast (DFC). DPC shows high sensitivity to changes in atomic number [31] and is therefore the ideal modality for the visualization of low-density material compositions such as biological tissue [32, 33] and the reduction of metal artifacts $[34,35]$. On the other hand, DFC visualizes scattering of X-rays, e.g., caused by small structures and defects like cracks or pores in a component. Since the DFC signal provides structural information on a sub-pixel scale, it is possible to quantify defects in larger specimens at relatively low resolution. Moreover, by using one-directional gratings in TLGI-XCT, the sensitivity of DFC is limited to the direction perpendicular to the grating orientation and can therefore be used for the determination of spatial orientation in microstructures [36, 37].

Current research is largely focused on the application of TLGI-XCT for medical diagnosis of chronic obstructive pulmonary diseases [38, 39] and breast cancer $[40,41]$ but also industrial applications such as the visualization of micro-cracks [42-45] and fiber orientation in (short-) CFRP [46-49]. For that purpose, continuous developments regarding the optimization of gratings [50,51], interferometer setup [52, 53] and reconstruction methods [54, 55] as well as image processing and visualization [56, 57] are still necessary in order to tackle the limitations of the technology [58].
For completeness, it should be mentioned, that there are several more methods for the extraction of DPC and DFC data explained in the literature. Endrizzi [59] provides a comprehensive overview of phase-contrast imaging techniques including analyzer crystal, propagation, edge illumination and tracking-based methods. Similarly to TLGI-XCT, these methods have shown to be suitable for biomedical and industrial applications such as mammography [60, 61], inspection of electronic components [62] and impact damage in CFRP [63].

In this work, we investigated vacuum infusion CFRP specimens extracted from larger airplane components, focusing on curved regions that cause a bending of the internal carbon fibers and a disruption of the internal meso-structure. Since TLGI-XCT is capable of detecting scattering structures in the subpixel regime [64], requirements in spatial resolution for the identification of carbon fibers are considerably reduced. Therefore, carbon fibers as well as resin-rich areas in relatively large components can be characterized at once [65] and additional insights into resinrich areas in combination with local carbon fiber layup and orientation can be found. These insights provide additional, more detailed input for finite elements simulations and consequently enable more reliable predictions for service life. Furthermore, with the implementation of presented methods to product quality control, the additional information can be used for optimization of CFRP production processes and increase cost efficiency.

\section{Materials and methods}

\section{Specimens and preparation}

Investigations were performed on six specimens cut from a vacuum infusion-manufactured CFRP component used in passenger aircraft. The laminate was formed by biaxial $\pm 45^{\circ}$ chain stitched non-crimp fabrics. The resin used for the infusion was CYCOM ${ }^{\circledR}$ 977-20 RTM, which is liquid at room temperature and cured in $3 \mathrm{~h}$ at $177^{\circ} \mathrm{C}$. The specimens were cut from regions with high local bending of the carbon fiber layers, which are typical hot spots for inhomogeneities occurring from the manufacturing process. The specimen dimensions were chosen to fit the specifications of the TLGI-XCT device used, resulting in sample dimensions of roughly 
$17 \times 10 \times 3 \mathrm{~mm}^{3}$. In most CFRP materials, attenuation contrast between carbon fibers and matrix material is too low for a sufficient segmentation and extraction of fiber orientation. However, visualization of single carbon fibers is possible but usually limited to a volume of only a few $\mathrm{mm}^{3}$ because of the magnification in cone-beam XCT and limited detector size. Therefore, compared to the dimensions of typical airplane components, the covered volume seems rather limited but is still relatively large for the determination of carbon fiber orientation, compared to standard absorption XCT $[5,11]$.

\section{Experimental setup and parameters}

\section{Conventional XCT}

Standard absorption XCT measurements were taken on a Nanotom 180NF (GE Sensing \& Inspection Technologies $\mathrm{GmbH}$, Germany) to complement TLGI-XCT measurements as reference volume data. The Nanotom device is equipped with a nano-focus tube, a molybdenum target and a $2304 \times 2304$ pixel Hamamatsu detector (Hamamatsu Photonics K.K., Japan). Scanning parameters are listed in Table 1.

\section{Talbot-Lau grating interferometer XCT}

For the extraction of fiber information as well as resin-rich areas, TLGI-XCT was performed using a SkyScan 1294 desktop system (Bruker microCT, Belgium), equipped with a $60 \mathrm{kV}$ micro-focus tube and a $4000 \times 2672$ pixel CCD camera. The grating interferometer consists of two absorption (G0 and G2) and one phase grating (G1), with grating periods of $4.8 \mu \mathrm{m}$, positioned in a symmetric setup (equidistantly) along the beam path (see Fig. 1). The G0 grating is placed directly in front of the X-ray source to create an array of line sources for a minimum required spatial coherency. The phase grating G1 causes a phase shift in fifty percent of the incoming $\mathrm{X}$-rays, leading to an interference with the remaining, non-shifted X-rays. This interference creates the projection of a self-image of the phase grating in repeated distances, which is referred to as Talbot effect [66].

At the given pixel size of the detector, this interference pattern cannot be visualized directly, necessitating an additional analyzing mechanism. For this purpose, the G2 absorption grating is positioned directly in front of the detector. In combination with a stepwise lateral movement of the G0 grating over one period of its own, also referred to as phase stepping [67], a sinusoidal intensity modulation is generated on each detector pixel. For measurements done in this work, 4 phase steps were performed during this procedure. The placement of a specimen in the beam path causes changes in this signal depending on the object's absorption, refraction and scattering properties. Compared to the reference signal without an object, three modalities can be extracted. The change in overall intensity of the signal yields the standard $\mathrm{AC}$, while a phase shift caused by refraction and a reduction of the signal amplitude by small-angle scattering is extracted as DPC and DFC, respectively. With knowledge about interferometer settings/geometry, DPC and DFC gray values can be converted directly to the refractive index decrement $\delta$ [68] and linear diffusion coefficient $\varepsilon$ [69]. Prior to every scan, the $\mathrm{X}$-ray tube was conditioned for a minimum of $2 \mathrm{~h}$, to allow a sufficient system warmup and avoid artifacts due to temperature drifts causing misalignments in the interferometer gratings. Furthermore, voxel size in $x-y$ and $z$ orientation was calibrated by precedent measurement of a voxel size calibration phantom designed for this system (ruby ball bar, distance from sphere to sphere: $12 \mathrm{~mm}$; DAkkS certificate diameter, form and distance sphere to sphere). Detailed parameters for scans performed are listed in Table 1.

Table 1 Scanning parameters for standard- and TLGI-XCT

\begin{tabular}{llllllrr}
\hline XCT-System & $\begin{array}{l}\text { Voxel } \\
\text { size }(\mu \mathrm{m})\end{array}$ & $\begin{array}{l}\text { Voltage } \\
(\mathrm{kV})\end{array}$ & $\begin{array}{l}\text { Current } \\
(\mu \mathrm{A})\end{array}$ & $\begin{array}{l}\text { Exposure } \\
\text { time }(\mathrm{ms})\end{array}$ & Projections & $\begin{array}{c}\text { Averaging } \\
\text { Pre-filter } \\
(\mathrm{mm})\end{array}$ & $\begin{array}{l}\text { Time } \\
(\mathrm{min})\end{array}$ \\
\hline Nanotom 180 NF & 11.4 & 60 & 300 & 600 & 1400 & 5 & - \\
SkyScan 1294 & 22.8 & 40 & 1100 & 600 & 1500 & 8 & $0.5 \mathrm{Al}$ \\
\hline
\end{tabular}




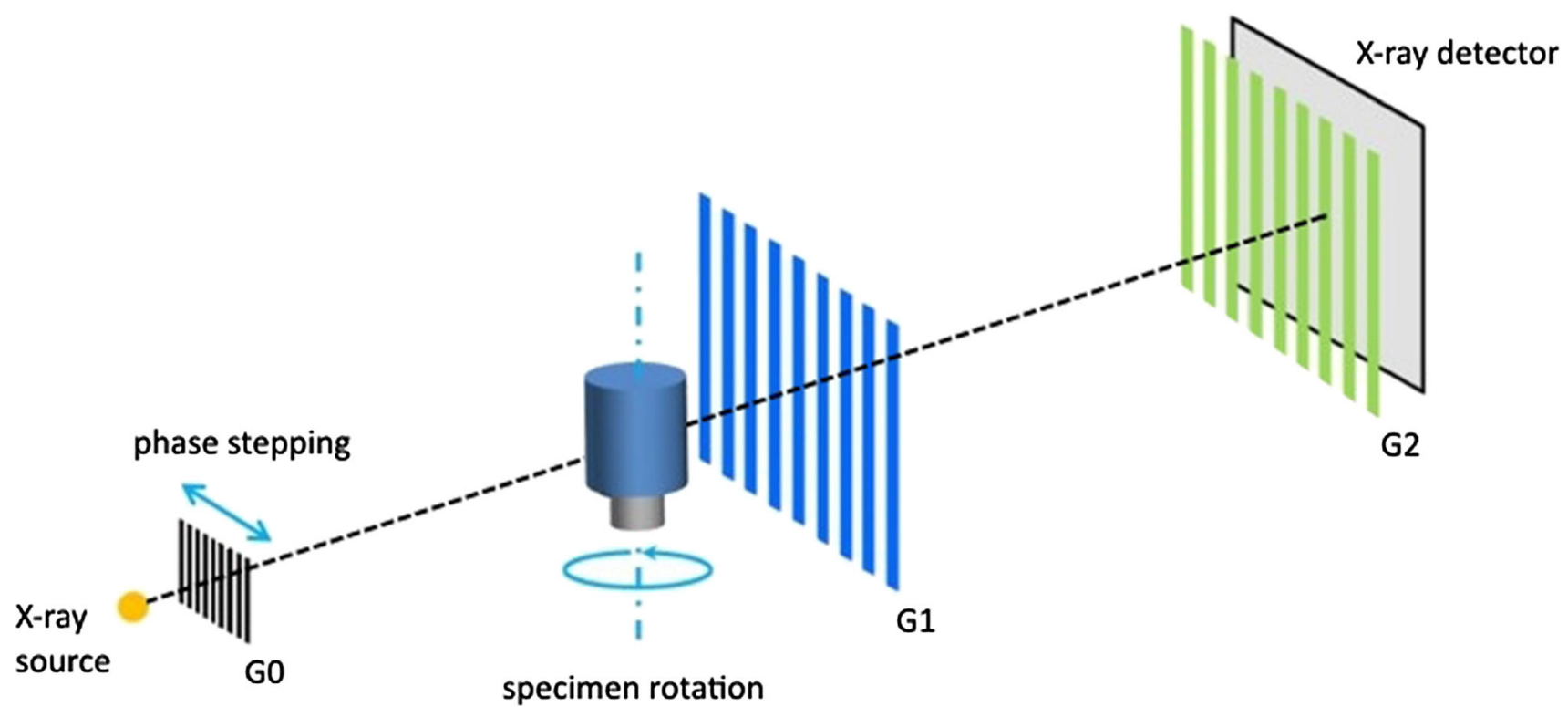

Figure 1 Schematic of the symmetric grating interferometer setup of the SkyScan 1294. Source (G0), phase (G1) and analyzer grating (G2) as well as X-ray source, detector and specimen position are indicated. Adapted from [34].

As the sensitivity of DFC is limited to the direction perpendicular to the grating orientation, information about fiber orientation can be extracted [36, 37, 70]. Therefore, by performing repeated measurements and sample repositioning, fiber orientations in a composite component can be evaluated. Since the exact fiber-layup of the investigated CFRP specimens was initially unknown, the first two necessary scan orientations were determined by the visible alignment of the surface layer and a position rotated by $90^{\circ}$ to it. Bright bands visible in the cross-sectional images (see Fig. 3) indicate a maximum scatter signal, which occurs at a horizontal alignment of fiber bundles during the CT scan. From these, 8 layers in $0^{\circ}$ and four double layers in $90^{\circ}$ orientation could be identified. Nevertheless, information of several volume layers was still missing. Consequently, assuming a standard layup of $0^{\circ} / 90^{\circ} /+45^{\circ} /-45^{\circ}$ plies, two additional scans were performed with the specimen rotated by $45^{\circ}$ in the ply-plane with respect to the initial orientation. In the cross-sectional images of these scans, three double and two single layers in + $45^{\circ}$ and eight single layers in $-45^{\circ}$ direction became visible. The resulting scanning positions were named accordingly (see Fig. 2).

With a total of four scans, we were able to identify the layer sequence of each specimen. However, in regions with strongly bent layers, fiber orientation in $\pm 45^{\circ}$ plies mismatched the horizontal alignment in the interferometer, resulting in a reduction of the scatter signal (see Fig. $3, \pm 45^{\circ}$ orientations). Subsequently, two more scans with tilted positioning to correct the alignment and complete the datasets were performed. This is done by examining the projection data to find the rotational position of the specimen at which the scatter signal is reduced by misalignment. Around that position, a tilt angle has to be empirically determined, until a peak in the scatter signal is visible at the respective region. This peak indicates a parallel alignment of the fiber bundles to the optical axis which means the horizontal alignment criteria is met.

\section{Image processing and visualization}

Extraction of image modalities from TLGI-XCT projection data and following reconstruction was performed with the software X-AID (MITOS GmbH, Germany) by means of a filtered back-projection algorithm with ring artifact correction. Image data of standard XCT reference scans was reconstructed using the GE phoenix datos I $\mathrm{x}$ software (GE Sensing \& Inspection Technologies $\mathrm{GmbH}$, Germany). Apart from the mentioned, no additional beam hardening correction or noise reduction filtering was applied. Alignment of attenuation contrast data of individual scans was done in Volume Graphics Studio 3.3 (Volume Graphics GmbH, Germany) by a best fit 


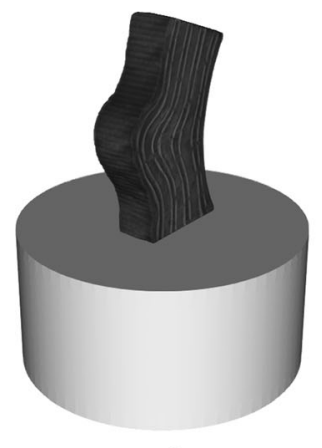

$0^{\circ}$

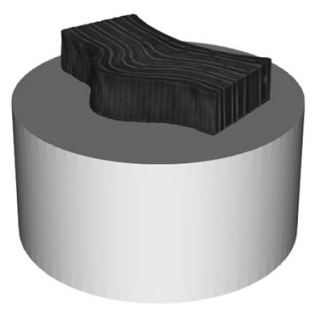

$90^{\circ}$

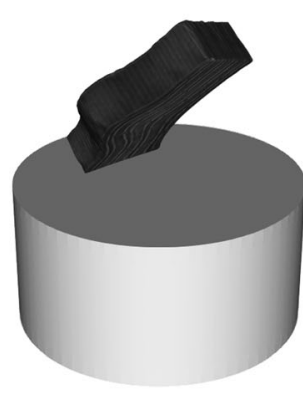

$+45^{\circ}$

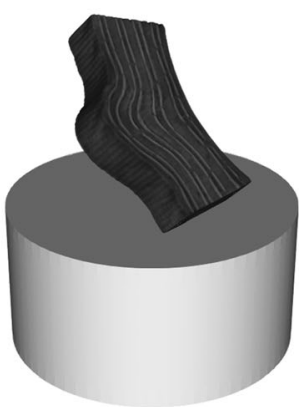

$-45^{\circ}$

Figure 2 Schematic of specimen positioning on a rotary table needed for visualization of individual fiber layer orientations. Angles correspond to deviation from vertical rotation axis.
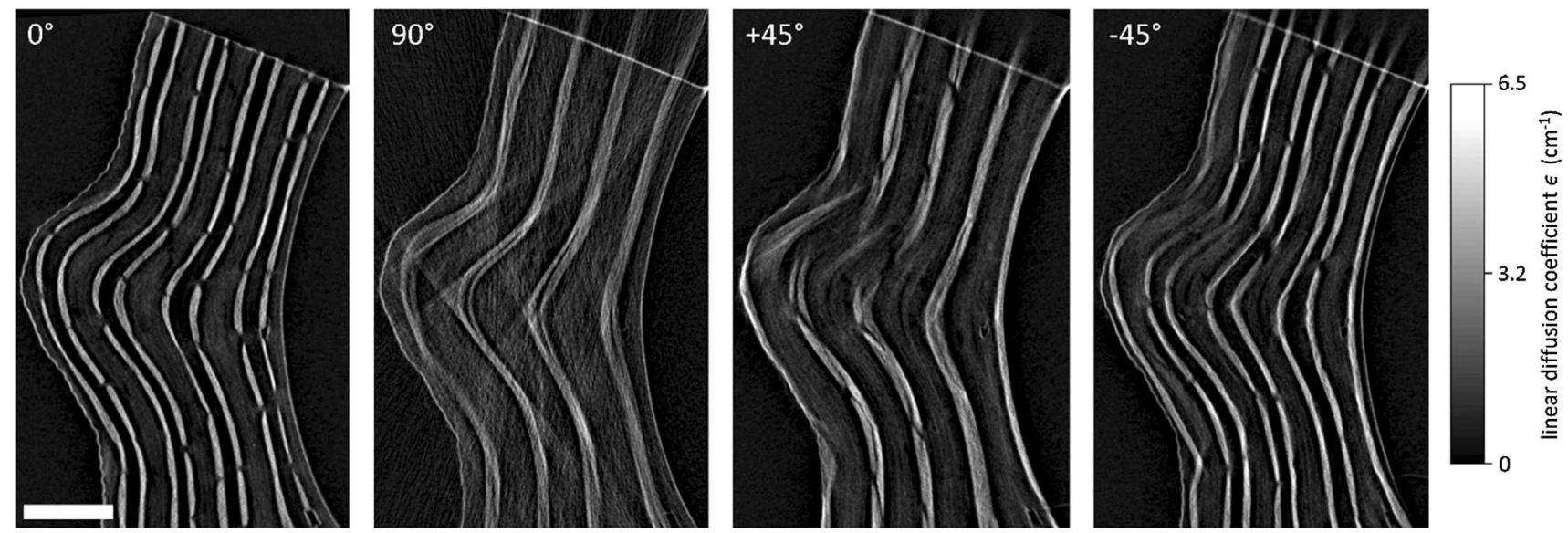

Figure 3 DFC cross-sectional images of specimen 1, recorded in four scan orientations. Regions with higher scattering (caused by carbon fibers and specimen surface) appear brighter. Interruptions in carbon fiber layers are caused by fiber collimation from binder

algorithm. Subsequently, the transformation could be transferred to DPC and DFC data from the same measurements, since they are perfectly aligned to their AC counterpart inherently. Merging of tilted orientation scans was also performed in Volume Graphics Studio 3.3.

Image fusion of several DFC layer data was performed in Avizo 2019.4 (Thermo Fisher Scientific Inc., USA). Prior to the fusion, non-local means (NLM) filtering with a search window of 10 pixels, a local neighborhood value of 5 pixels and similarity value 0.3 was applied in order to reduce the influence of image noise and artifacts among the datasets. Parameters of the NLM filter were determined empirically to reduce image noise without losing information on fiber layers. yarn. Especially in $90^{\circ}$ orientation, regions with low fiber content between two adjacent $90^{\circ}$ layers are visible. The scale bar corresponds to $2500 \mu \mathrm{m}$.

\section{Results}

\section{Fiber orientation and layer identification}

With four scans performed, we determined a total of 32 layers in a sequence of $\left[+45^{\circ} /-45^{\circ} / 0^{\circ} / 90^{\circ}\right] 4 S$. Cross-sectional images of individual scans and sample orientations are shown in Fig. 3, while the evaluated layer sequence is visualized schematically in Fig. 4. Interruptions in the fiber layers as well as dark/black regions between two adjacent layers, especially visible between $90^{\circ}$ and $+45^{\circ}$ scans, indicate the absence of fibers and consequently a possible development of resin-rich areas. Because of the vertical orientation of gratings and sample rotation around the same direction, scatter properties in a single volume element change in dependence of the rotation angle leading to streaking artifacts in the 

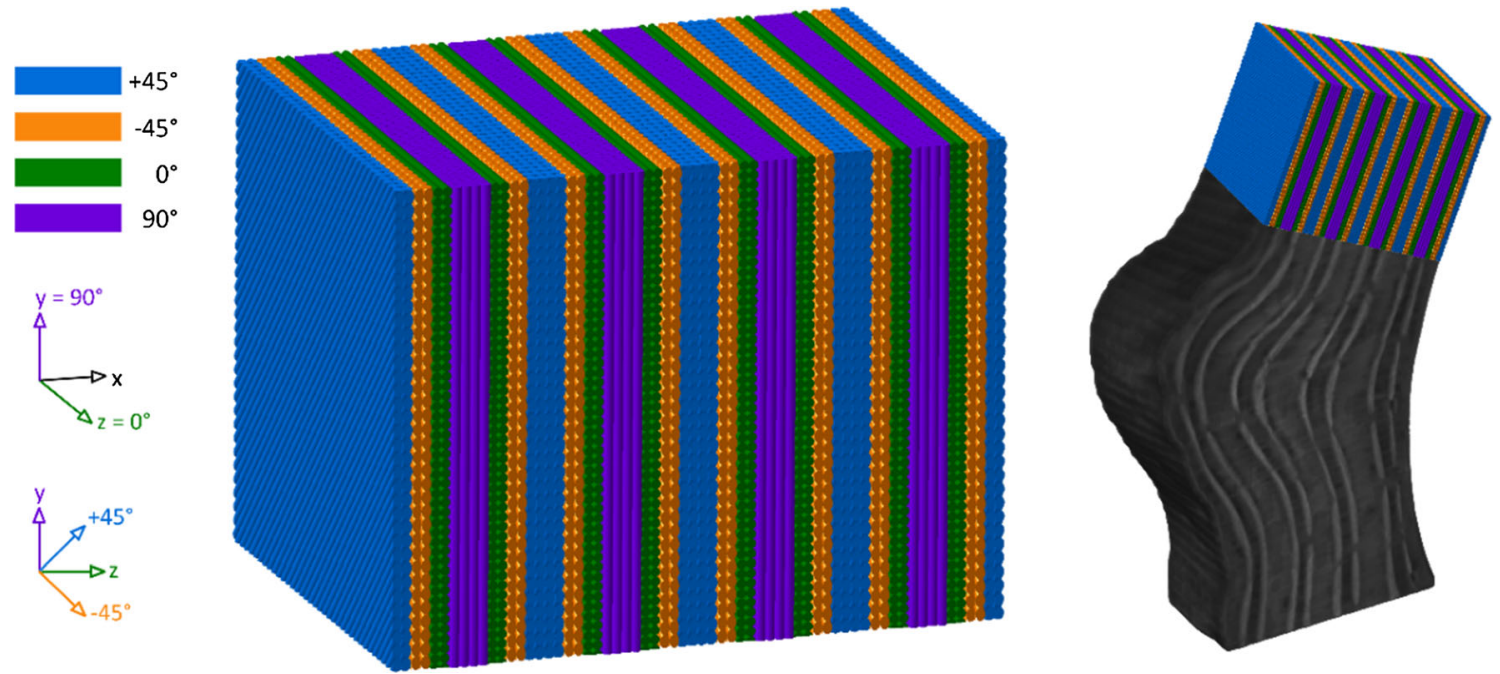

Figure 4 Schematic visualization of the layer sequence $\left[+45^{\circ} /-45^{\circ} / 0^{\circ} / 90^{\circ}\right] 4 \mathrm{~S}$, determined via DFC imaging. Colors represent different orientations of fibers. The alignment of layers in reference to specimen 1 is shown on the right.

data [36]. For example, this is visible in $90^{\circ}$ scan data, in which penetration length changes considerably due to specimen orientation. Since material interfaces cause a scattering signal, the specimen surface is characterized by a rather thin white band in all orientations, not to be confused with scattering caused by carbon fibers.

Residual information about fiber layers in strongly bent regions was acquired with two additional scans in tilted orientation. Tilted data was merged with original scan orientations to create a single dataset with complete layer information (e.g., see Fig. 7a). Therefore, using a total of 6 scans, the whole volume of a specimen was characterized in relation to fiber orientation in the respective layer. Figure 5 shows 3D renderings of individually oriented fiber layers as well as resin-rich areas.

\section{Defect characterization}

\section{Resin-rich areas}

Figure 6 shows a standard XCT measurement at a resolution of $(11.4 \mu \mathrm{m})^{3}$ voxel size in comparison with a DPC image at $(22.8 \mu \mathrm{m})^{3}$ voxel size. In contrast to AC images, the resin in DPC images appears darker than the surrounding composite because of its lower refractive index. Differences in AC and DPC become obvious in zoomed sections of Fig. 6 and when line profiles are applied over a resin-rich area. In particular at relatively thin layers of resin, DPC still shows a clearly visible peak in contrast to AC.
Streak artifacts in direction along the beam axis in DPC are caused by phase wrapping effects typically occurring at material interfaces causing a high phase shift [71].

From the comparison of DPC and DFC image data, we found that resin-rich areas can develop between fiber layers (inter-layer) as well as within individual layers (in-layer). Especially using color-coded visualizations of individual fiber layer orientations in DFC, in- and inter-layer resin-rich areas are easy to differentiate (see Fig. 5e). This leads to the finding that inter-layer resin-rich areas are more pronounced in regions with high bending of the layers and within these regions, largest resin zones are located between $90^{\circ}$-oriented layers. For further investigation, we applied non-planar cross sections along single fiber layers, to visualize only in-layer resin-rich areas. The results in Fig. 7c reveal the rhomboidal-shaped characteristic of the resin zones caused by the collimation of fibers by binder yarns as observed in several previous studies [16, 26, 72].

Repeatedly appearing binder yarn collimation sites can overlap each other, in some cases creating resin pockets penetrating through several layers of carbon fibers. In a 3D rendered visualization, such overlapping resin areas often appear in a cross-shaped way (see Fig. 5f). An example of a resin pocket penetrating through 5 carbon fiber layers is indicated in Fig. $7 b$. Furthermore, after CT measurements were completed, specimen 1 was prepared for microsections to visualize resin pockets with embedded 
Figure 5 Specimen 1; ad $3 \mathrm{D}$ rendering of $0^{\circ}$, $90^{\circ},+45^{\circ}$ and $-45^{\circ}$ fiber layers. The fiber layers were segmented by standard ISOthresholding, followed by advanced surface determination method (local gray value gradients) in Volume Graphics Studio 3.3. e 2D slice image of combined fiber layers. Regions with low fiber content inside and between layers appear as dark/ black regions. $f$ $3 \mathrm{D}$ rendering of resin-rich areas segmented from DPC. Resin-rich areas were defined by a first, rough segmentation by regiongrowing algorithm, followed by advanced surface determination method in Volume Graphics Studio 3.3. Cross-shaped resin areas come from overlapping binder yarn collimation sites in adjacent layers (diagonal crosses in $\pm 45^{\circ}$ layers, horizontal/ vertical crosses in $0^{\circ} / 90^{\circ}$ layers).
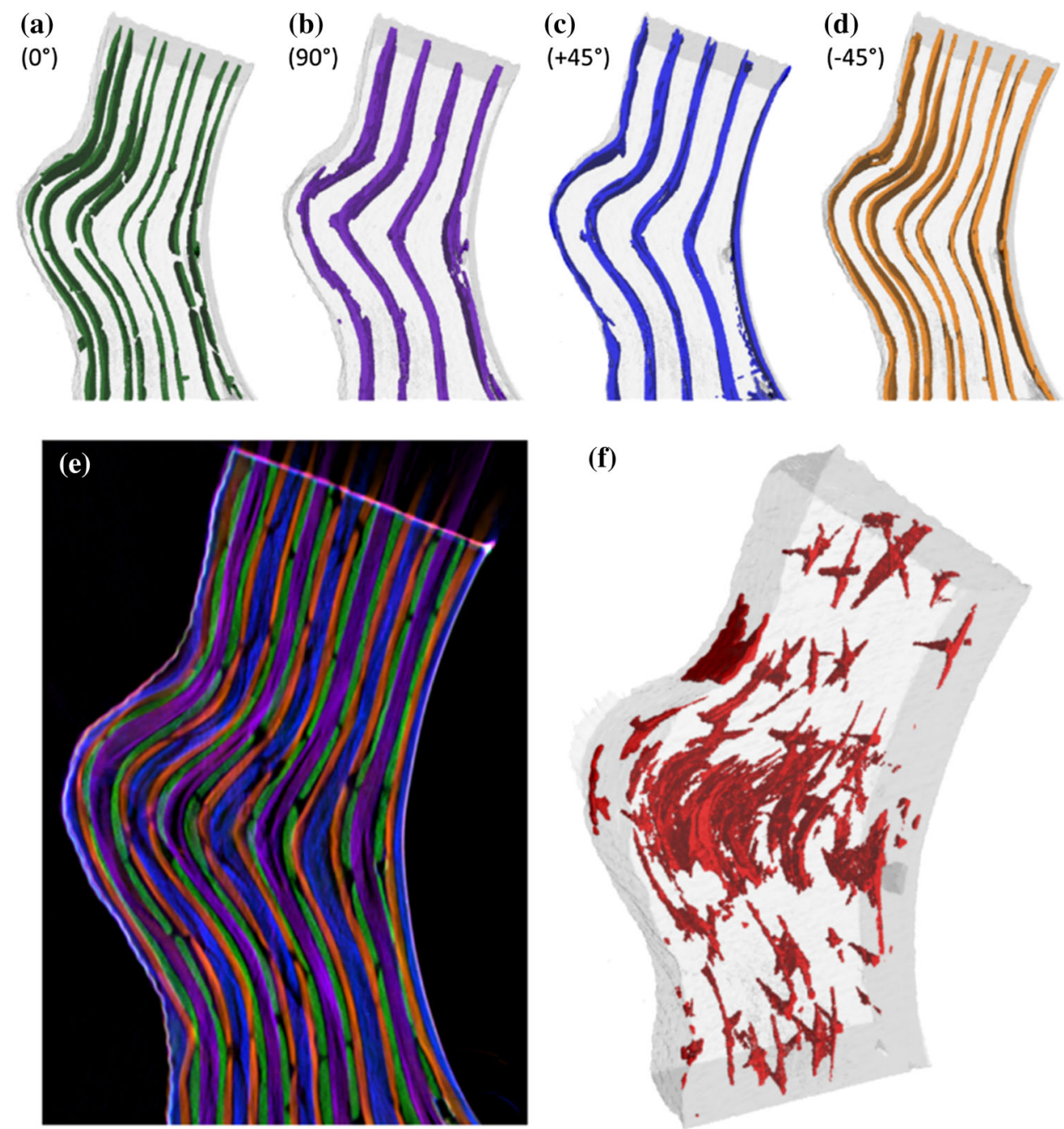

(f)
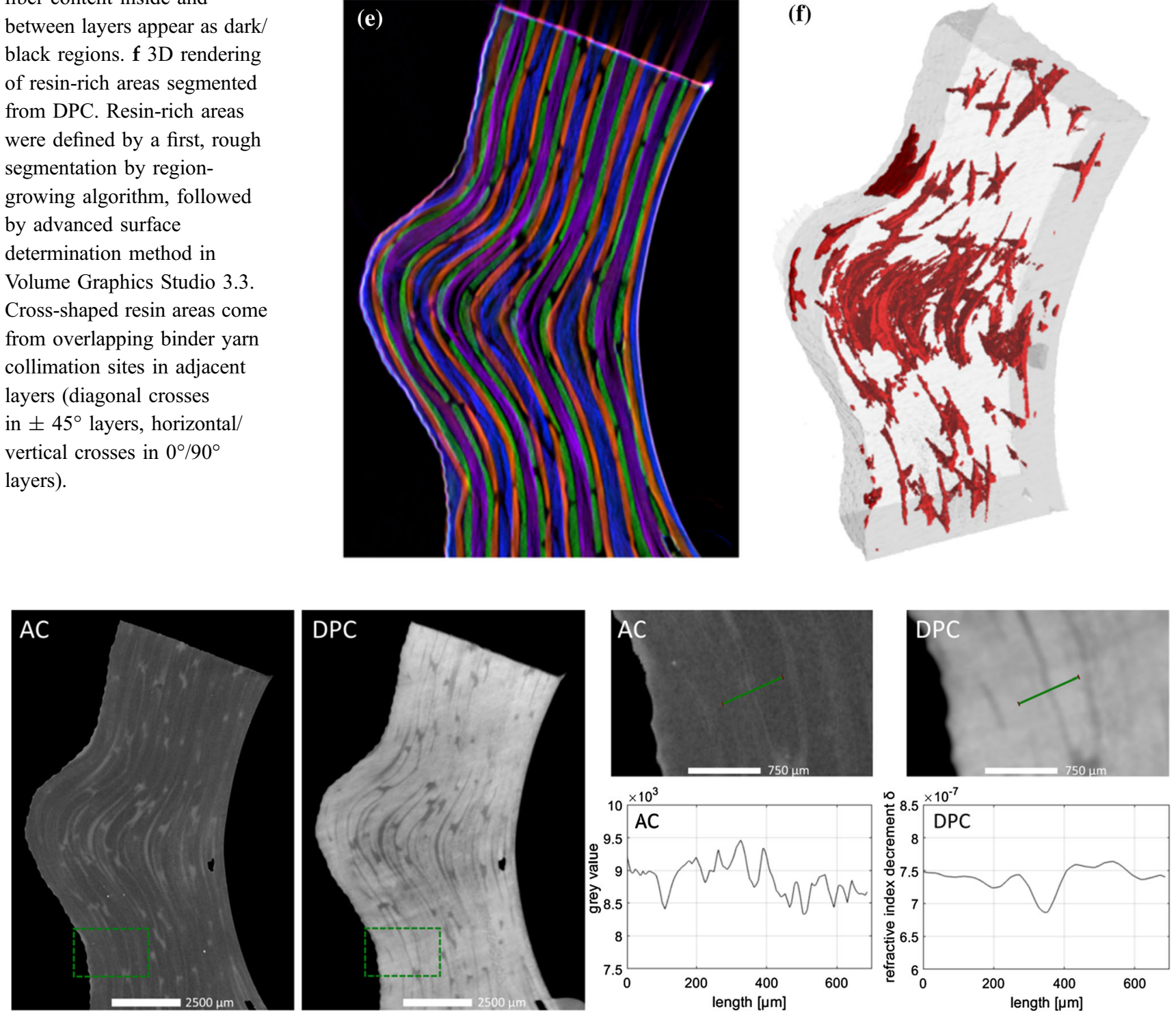

Figure 6 Comparison of AC and DPC imaging of Specimen 1. Resin-rich areas appear brighter than carbon fibers in $\mathrm{AC}$ and darker in DPC. Zoomed sections show a thin resin zone. Line profile plots reveal the enhanced contrast of DPC. Streak artifacts in DPC are caused by phase wrapping effects. 

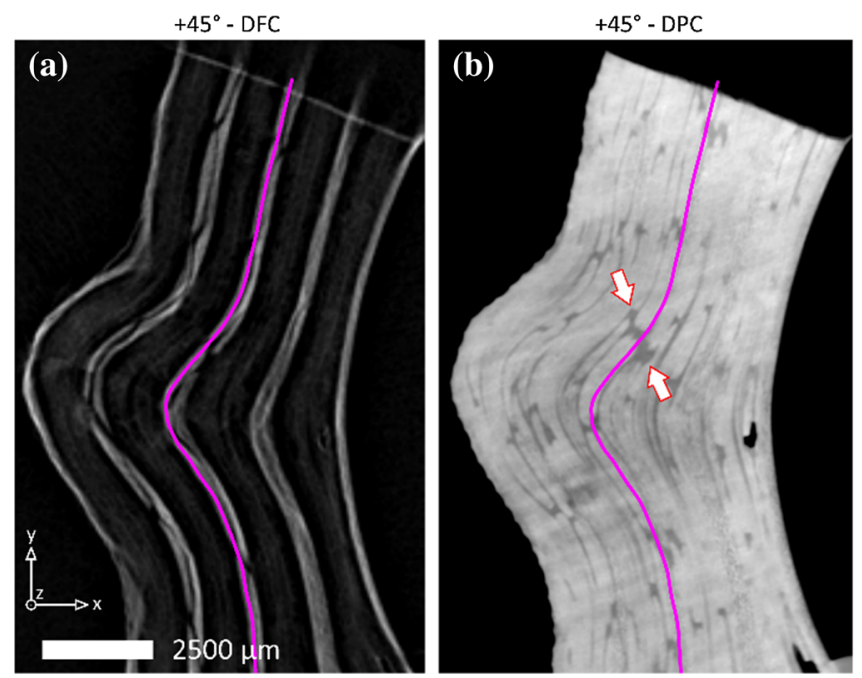

Figure 7 Specimen 1; a, b Exemplary cut sections along a $+45^{\circ}$ layer are indicated in a DFC and DPC slice image. A resin zone penetrating through five layers is indicated with arrows in (b). c Non-planar cross sections through differently oriented layers

binder yarns. In Fig. 8, the same resin pocket penetrating through 5 fiber layers is visualized by reflected light optical microscopy at 50 and 100 times magnification, respectively.

\section{Void space}

Inter-layer resin-rich areas are prominent in regions where CFRP layers are strongly bent and a mismatch between the fiber layers or layers and mold occurs [21]. This can also cause an insufficient infusion of resin, leading to voids of air between the fibers. These voids are not only limited to inter-layer space, but also develop in regions in which fibers are collimated by binder yarns. From our investigations of six infusion specimens, we found that $46.4 \%$ of the occurring void volume over all specimens is located between two $90^{\circ}$ or their adjacent layers. This means a roughly $20 \%$ increased void occurrence in these regions compared to a random distribution over all 31 inter-layer spaces of each specimen. Detailed results of porosity analyses are listed in Table 2 as well as corresponding slice images are shown in Fig. 9.

\section{Discussion}

The capability of TLGI-XCT to detect scattering structures in the sub-pixel regime [64] significantly reduces the required spatial resolution for

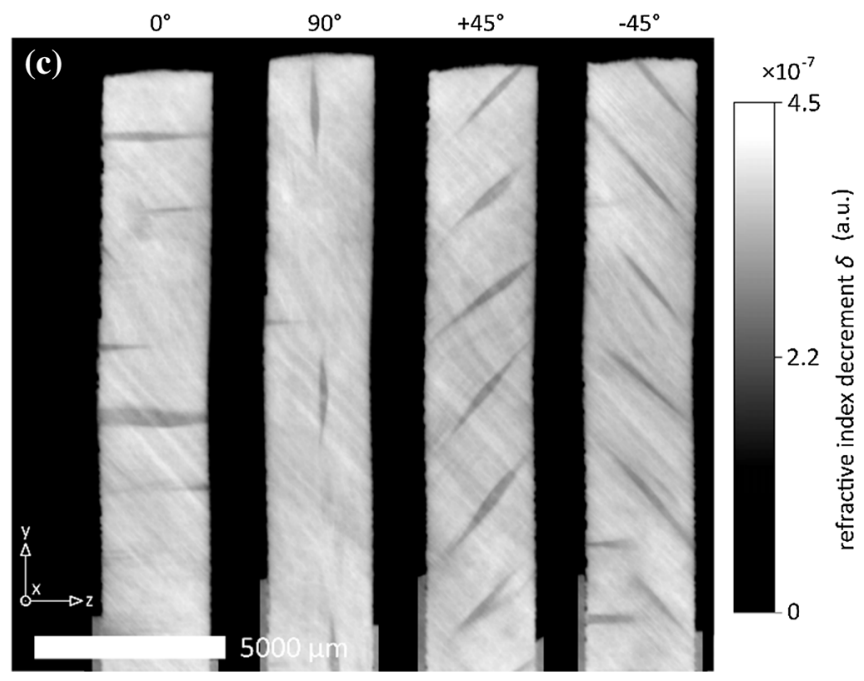

revealing in-layer rhomboidal resin areas caused by binder yarn collimation. Streak artifacts in DPC are caused by phase wrapping effects.

identification of carbon fiber layers. Moreover, combining the directional sensitivity of DFC and knowledge of the orientation of a visible single fiber layer located at the specimen surface, composite layup, individual fiber layers and their orientation can be readily extracted. Therefore, layers oriented in the same direction as this visually identifiable surface layer were determined by scanning the specimen in the corresponding position with respect to grating direction. The orientations of the remaining layers and the respective specimen placements were subsequently concluded using the information gained from the preceding scans. In that way, the layer sequence was determined with 4 scan positions. This methodology is applicable for standard laminate layups where at least the orientation of an initial layer is known. If this is not the case, prior investigations to evaluate the approximate fiber layer orientations are necessary. This can for example be done by TLGI radiography, as fiber bundles aligned parallel to the optical axis will show a distinct peak in the scatter signal [49]. An approximate assessment of the fiber layup can therefore be done in relatively short time, as radiography images are typically available in live view. However, strongly bent layers can be difficult to visualize because of changes in DFC intensity due to the non-uniform fiber directions. Therefore, in some cases, additional scans are necessary to cover regions with lack of information as visible in Fig. 3 at $\pm 45^{\circ}$ orientations. The increased amount of scans 


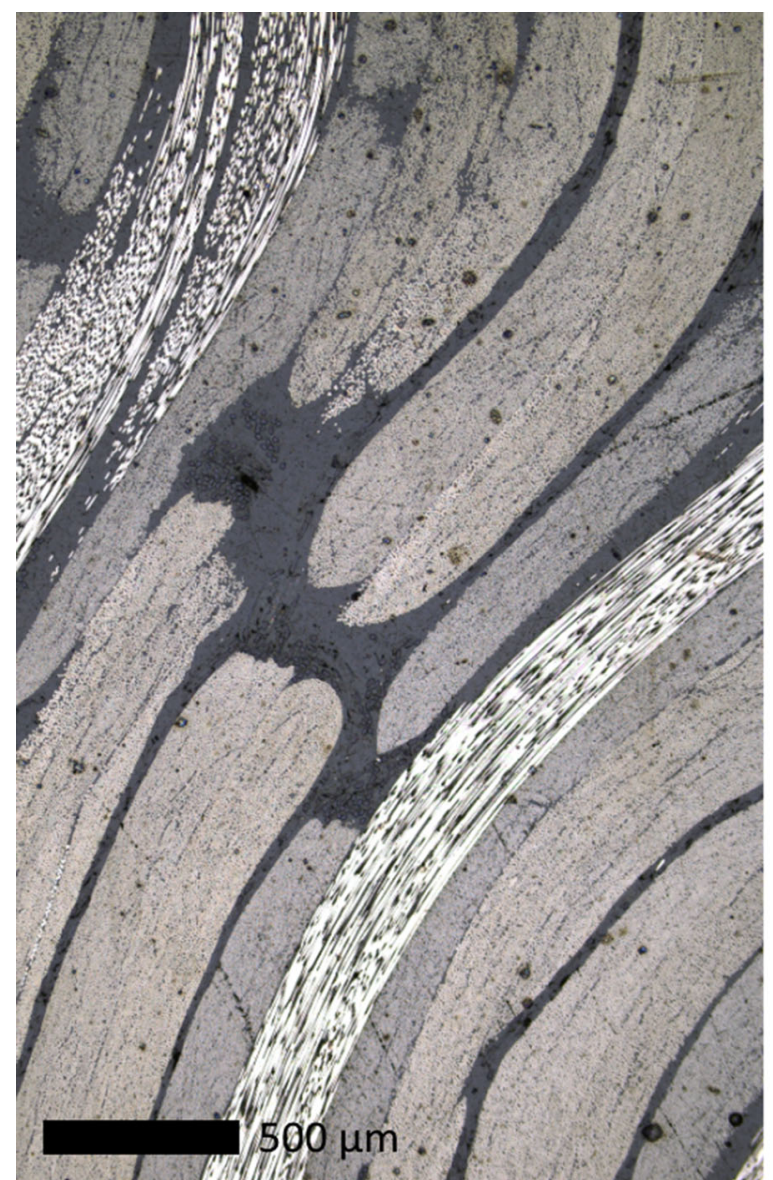

Figure 8 Microsection images of specimen 1 recorded at 50 and 100 times magnification showing dark resin-rich areas between brighter carbon fibers. A large resin pocket penetrating through 5

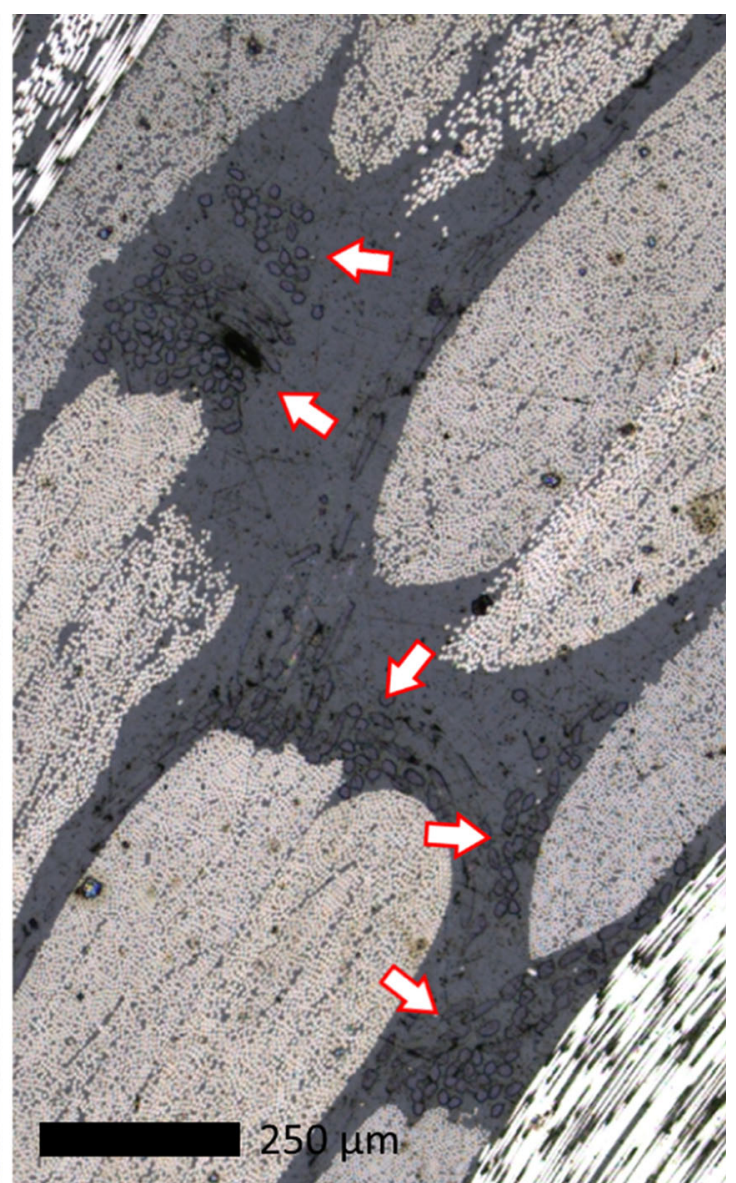

carbon fiber layers is visible at the center. Arrows were added to indicate binder yarns embedded in resin.
Table 2 Void volume evaluated in each specimen and between two $90^{\circ}$ or their adjacent layers only

\begin{tabular}{llll}
\hline Specimen & Void volume $\left(\mathrm{mm}^{3}\right)$ & Void volume- $90^{\circ}\left(\mathrm{mm}^{3}\right)$ & Void volume-90 $(\%)$ \\
\hline 1 & 0.3 & 0.0 & 0.0 \\
2 & 5.0 & 2.2 & 42.7 \\
3 & 2.3 & 0.8 & 34.4 \\
4 & 3.8 & 2.1 & 54.7 \\
5 & 2.4 & 1.4 & 60.8 \\
6 & 1.3 & 0.5 & 40.0 \\
Total & 15.1 & 7.0 & 46.4 \\
\hline
\end{tabular}

necessary for a single specimen in combination with the typically long scan times caused by the intensity reduction from absorption gratings and phase stepping approach makes TLGI generally rather timeconsuming. Additionally, for sake of image quality and constant measurement parameters over all scans performed the scan duration chosen was potentially exaggerated. At the given specimen dimensions, we experienced that a reduction to 375 projection images increases image noise but layer identification by DFC is still absolutely possible. We thereby achieved scan times below $170 \mathrm{~min}$ per orientation. Furthermore, for orientations with low transmission lengths (all except $90^{\circ}$ orientation) projections or image averaging could be reduced further to achieve scan times comparable to standard XCT. In addition, edge-preserving image filters or iterative reconstruction methods can be applied to counteract increasing 


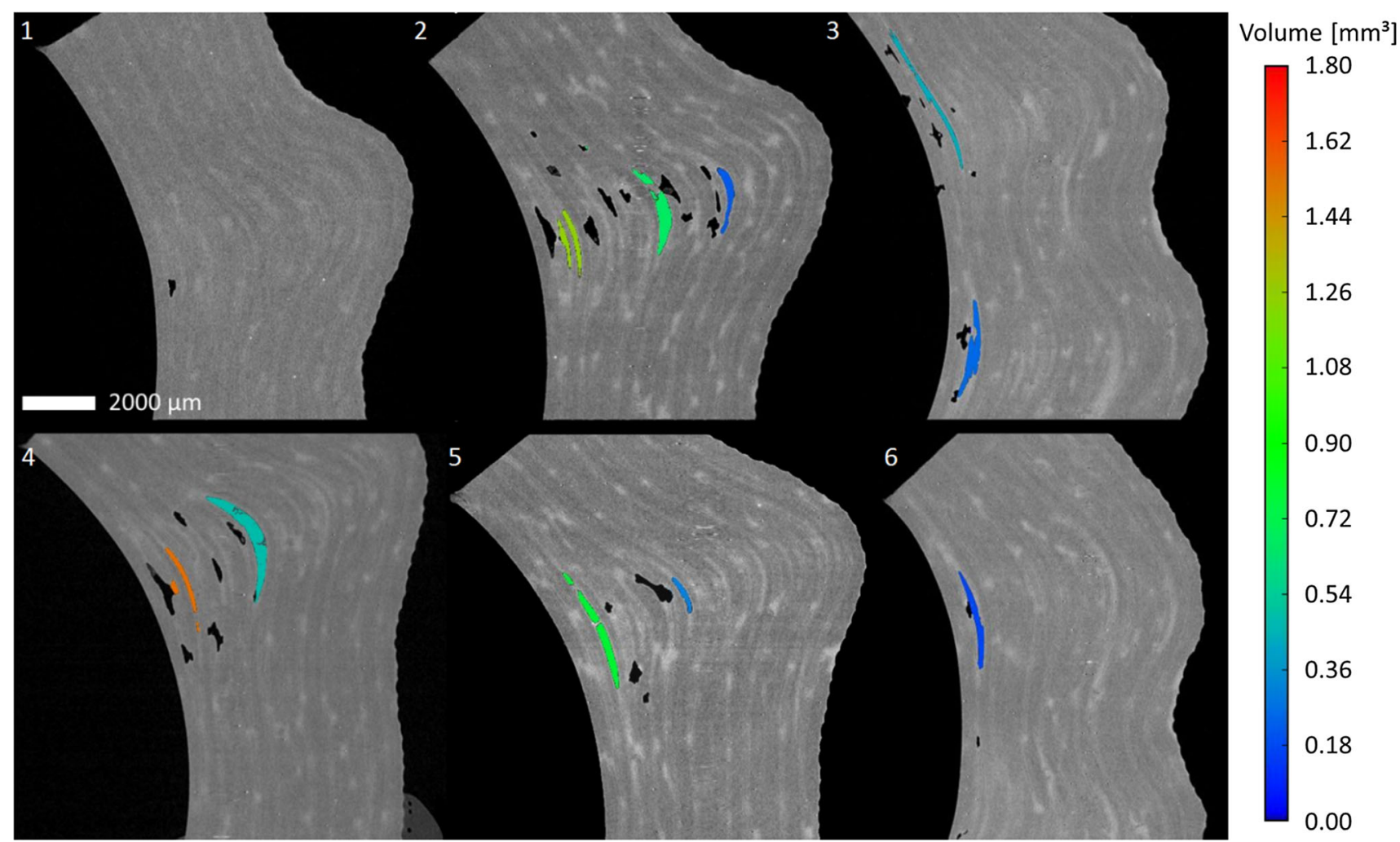

Figure 9 AC slice images of specimens 1-6 from top left to bottom right (voxel size $\left.(22.8 \mu \mathrm{m})^{3}\right)$. Color-coded defects are situated between two $90^{\circ}$ or their adjacent layers.

image noise at reduced scan times if necessary. Moreover, the SkyScan 1294 system is rather limited in applicable voltage (maximum $50 \mathrm{kV}$ ) as its absorption gratings of $40 \mu \mathrm{m}$ height are too transmissive for higher energy photons. Current state-ofthe-art gold gratings can be manufactured with heights of more than $120 \mu \mathrm{m}$ and curvature fitted to the cone-beam geometry, increasing both the applicable energies and field of view.

For the investigation of resin-rich areas, a single scan is typically sufficient, although the reduction of projections and/or averaging does affect the detectability of resin-rich areas in DPC more severely. In combination with fiber layup identification from DFC data, further conclusions about the cause for certain resin-rich areas are possible. Dong [21] experimentally observed the cause for resin-rich areas between fibers and mold via microscopy in regions characterized by significantly bent layers, resulting in a collimation of fibers. We were able to confirm these observations at regions of interest in an actual aerospace component (see Fig. 7a, b). Furthermore, in [21] only simple bending scenarios of $90^{\circ}$ and $135^{\circ}$ were performed to provoke the formation of resin zones between fibers and mold. We also found that at more complex bending scenarios, gaps filling with resin can form between individual fiber layers as well. This is particularly obvious between two adjacent layers of $90^{\circ}$ orientation, which are characterized by large resin pockets.

However, also binder yarn collimation sites cause resin pockets in composites [16, 26, 72]. As shown in Fig. $7 \mathrm{~b}$, these pockets can penetrate through several layers of carbon fibers as they are overlapping each other. Consequently, the formation of such penetrating resin zones is already determined by the placement of fiber sheets in the mold and could possibly be avoided by a shifted arrangement. In extreme cases, the cavities formed by disturbances in the layer sequence can also lead to an insufficient infusion with resin, leaving voids in the composite volume. Since inter-layer resin-rich areas are more pronounced between layers of $90^{\circ}$ orientation, we did further investigations revealing that the amount of void volume located between $90^{\circ}$ or their adjacent layers is also increased by roughly $20 \%$ compared to a random 
distribution over all inter-layer spaces. Voids in other layers are induced mainly by binder yarn collimation sites.

The additional insights into CFRP laminates gained by TLGI-XCT provide extended structural information for virtual models on a mesoscale facilitating finite element (FE) analyses. Predictions of material behavior of complex CFRP parts necessitate reliable FE simulations that largely depend on accurate experimental data from mechanical tests of physical samples. Detailed knowledge about resin-rich areas and their three-dimensional distribution in composites as well as fiber layup and orientation can therefore contribute to elaborate models for finite elements simulations [25, 27]. Consequently, future works will focus on the implementation of these findings into finite elements models for prediction of mechanical strength and damage initiation. Furthermore, increased scan time of TLGI-XCT in comparison with standard XCT reduces the applicability of the method for quality control in industry. Ongoing research therefore aims a reduction of scan time, e.g., by use of iterative reconstruction methods to reduce the number of necessary projection images.

\section{Conclusion}

In contrast to previous studies, this work focuses on the characterization of resin-rich areas and voids in vacuum infusion CFRP through combined information gained by additional image modalities from TLGI-XCT. We have successfully utilized the directional sensitivity of DFC imaging for the determination of an unknown layer sequence. Thereby, the low requirements in spatial resolution enable the characterization of a relatively large volume element in comparison with standard XCT. Furthermore, the high sensitivity of DPC imaging to differences in atomic number was used for the investigation of resin-rich areas in specimens measured. Subsequently, we showed that the information gained from these complementary image modalities can be used to differentiate between in- and inter-layer resin-rich areas and to make more precise conclusions about their cause. Hence, we found that inter-layer resinrich areas are more pronounced in regions where fiber layers are strongly bent, especially between layers with fibers oriented in bending direction. Other than that, resin-rich areas are mostly caused by the collimation of fiber tows by binder yarn. These findings also correlate with the development of voids in the specimens.

\section{Acknowledgements}

This work was financed by the project "Phad-CT" funded by the federal government of Upper Austria [FFG Grant Number: 875432], by "SpaceNDT" funded by the federal ministry for climate action, environment, energy, mobility, innovation and technology and the Austrian Space Applications Programme [FFG Grant Number: 866013] and by Operational Programme Research, Development and Education in the project INAFYM (CZ.02.1.01/0.0/ 0.0/16_019/0000766). The authors also thank Patrick Kastenhofer for microsection preparation and measurements.

\section{Funding}

Open access funding provided by University of Applied Sciences Upper Austria.

\section{Compliance with ethical standards}

Conflict of interest The authors declare that they have no known competing financial interests or personal relationships that could have appeared to influence the work reported in this paper.

Open Access This article is licensed under a Creative Commons Attribution 4.0 International License, which permits use, sharing, adaptation, distribution and reproduction in any medium or format, as long as you give appropriate credit to the original author(s) and the source, provide a link to the Creative Commons licence, and indicate if changes were made. The images or other third party material in this article are included in the article's Creative Commons licence, unless indicated otherwise in a credit line to the material. If material is not included in the article's Creative Commons licence and your intended use is not permitted by statutory regulation or exceeds the permitted use, you will need to obtain permission directly from the copyright holder. To view a copy of this licence, visit http://creativecommons.org/licen ses/by/4.0/. 


\section{References}

[1] Che D, Saxena I, Han P et al (2014) Machining of carbon fiber reinforced plastics/polymers: a literature review. J Manuf Sci Eng Trans ASME. https://doi.org/10.1115/1. 4026526

[2] Guo Y, Xu Y, Wang Q et al (2019) Enhanced lightning strike protection of carbon fiber composites using expanded foils with anisotropic electrical conductivity. Compos Part A Appl Sci Manuf 117:211-218. https://doi.org/10.1016/j.composite sa.2018.11.022

[3] Symons DD (2000) Characterisation of indentation damage in 0/90 lay-up T300/914 CFRP. Compos Sci Technol 60:391-401. https://doi.org/10.1016/S0266-3538(99)001396

[4] Röper F, Plank B, Glinz J et al (2020) X-ray computed tomography in bonded aircraft repairs for composites. In: Proceedings of the 10th conference on industrial computed tomography. Wels, Austria, pp 1-6

[5] Plank B, Schiwarth M, Senck S et al (2019) Multiscale and multimodal approaches for three- dimensional materials characterisation of fibre reinforced polymers by means of X-ray based NDT methods. Proc Int Symp Digit Ind Radiol Comput Tomogr, pp 1-11

[6] McElroy M, Jackson W, Olsson R et al (2017) Interaction of delaminations and matrix cracks in a CFRP plate, Part I: a test method for model validation. Compos Part A Appl Sci Manuf 103:314-326. https://doi.org/10.1016/j.compositesa. 2017.09.011

[7] Nelson LJ, Smith RA (2019) Fibre direction and stacking sequence measurement in carbon fibre composites using Radon transforms of ultrasonic data. Compos Part A Appl Sci Manuf 118:1-8. https://doi.org/10.1016/j.compositesa.2 018.12 .009

[8] Kytýř D, Fíla T, Valach J, Šperl M (2013) Evaluation of impact damage effect on fatigue life of carbon fibre composites. UPB Sci Bull Ser D Mech Eng 75:157-164

[9] Mayr G, Plank B, Sekelja J, Hendorfer G (2011) Active thermography as a quantitative method for non-destructive evaluation of porous carbon fiber reinforced polymers. NDT E Int 44:537-543. https://doi.org/10.1016/j.ndteint.2011.05. 012

[10] Yuan Y, Wang S (2019) Measurement of the energy release rate of compressive failure in composites by combining infrared thermography and digital image correlation. Compos Part A Appl Sci Manuf 122:59-66. https://doi.org/10. 1016/j.compositesa.2019.04.022

[11] Emerson MJ, Jespersen KM, Dahl AB et al (2017) Individual fibre segmentation from $3 \mathrm{D}$ X-ray computed tomography for characterising the fibre orientation in unidirectional composite materials. Compos Part A Appl Sci Manuf 97:83-92. https://doi.org/10.1016/j.compositesa.2016.12. 028

[12] Hsiao HM, Daniel IM (1996) Effect of fiber waviness on stiffness and strength reduction of unidirectional composites under compressive loading. Compos Sci Technol 56:581-593. https://doi.org/10.1016/0266-3538(96)00045-0

[13] Wilhelmsson D, Gutkin R, Edgren F, Asp LE (2018) An experimental study of fibre waviness and its effects on compressive properties of unidirectional NCF composites. Compos Part A Appl Sci Manuf 107:665-674. https://doi. org/10.1016/j.compositesa.2018.02.013

[14] Fuoss E, Straznicky PV, Poon C (1998) Effects of stacking sequence on the impact resistance in composite laminatespart 1: parametric study. Compos Struct 41:67-77. https://d oi.org/10.1016/S0263-8223(98)00036-1

[15] Barile C, Casavola C, De Cillis F (2019) Mechanical comparison of new composite materials for aerospace applications. Compos Part B Eng 162:122-128. https://doi.org/10. 1016/j.compositesb.2018.10.101

[16] Leong KH, Lee B, Herszberg I, Bannister MK (2000) The effect of binder path on the tensile properties and failure of multilayer woven CFRP composites. Compos Sci Technol 60:149-156. https://doi.org/10.1016/S0266-3538(99)001086

[17] Kousourakis A, Bannister MK, Mouritz AP (2008) Tensile and compressive properties of polymer laminates containing internal sensor cavities. Compos Part A Appl Sci Manuf 39:1394-1403. https://doi.org/10.1016/j.compositesa.2008.0 5.003

[18] Shivakumar K, Emmanwori L (2004) Mechanics of failure of composite laminates with an embedded fiber optic sensor. J Compos Mater 38:669-680. https://doi.org/10.1177/ 0021998304042393

[19] Huang CY, Trask RS, Bond IP (2010) Characterization and analysis of carbon fibre-reinforced polymer composite laminates with embedded circular vasculature. J R Soc Interface 7:1229-1241. https://doi.org/10.1098/rsif.2009.0534

[20] Mehdikhani M, Gorbatikh L, Verpoest I, Lomov SV (2019) Voids in fiber-reinforced polymer composites: a review on their formation, characteristics, and effects on mechanical performance. J Compos Mater 53:1579-1669. https://doi.or $\mathrm{g} / 10.1177 / 0021998318772152$

[21] Dong C (2011) Model development for the formation of resin-rich zones in composites processing. Compos Part A Appl Sci Manuf 42:419-424. https://doi.org/10.1016/j.com positesa.2010.12.017

[22] Safonov A, Fedulov BN (2016) Method for computational modelling of residual stresses and stress-induced 
manufacturing defects in vacuum-infused automated placement laminates. Compos Nanostruct 8:29-46

[23] Hindersmann A (2019) Confusion about infusion: an overview of infusion processes. Compos Part A Appl Sci Manuf 126:105583. https://doi.org/10.1016/j.compositesa.2019. 105583

[24] Ogasawara T, Hirano Y, Yoshimura A (2010) Coupled thermal-electrical analysis for carbon fiber/epoxy composites exposed to simulated lightning current. Compos Part A Appl Sci Manuf 41:973-981. https://doi.org/10.1016/j.composite sa.2010.04.001

[25] Mikhaluk DS, Truong TC, Borovkov AI et al (2008) Experimental observations and finite element modelling of damage initiation and evolution in carbon/epoxy non-crimp fabric composites. Eng Fract Mech 75:2751-2766. https://d oi.org/10.1016/j.engfracmech.2007.03.010

[26] Truong TC, Ivanov DS, Klimshin DV et al (2008) Carbon composites based on multi-axial multi-ply stitched preforms. Part 7: mechanical properties and damage observations in composites with sheared reinforcement. Compos Part A Appl Sci Manuf 39:1380-1393. https://doi.org/10.1016/j.c ompositesa.2008.05.004

[27] Ghayoor H, Marsden CC, Hoa SV, Melro AR (2019) Numerical analysis of resin-rich areas and their effects on failure initiation of composites. Compos Part A Appl Sci Manuf 117:125-133. https://doi.org/10.1016/j.compositesa. 2018.11.016

[28] David C, Nöhammer B, Solak HH, Ziegler E (2002) Differential $\mathrm{x}$-ray phase contrast imaging using a shearing interferometer. Appl Phys Lett 81:3287-3289. https://doi.or $\mathrm{g} / 10.1063 / 1.1516611$

[29] Pfeiffer F, Weitkamp T, Bunk O, David C (2006) Phase retrieval and differential phase-contrast imaging with lowbrilliance X-ray sources. Nat Phys 2:258-261. https:/doi. org/10.1038/nphys265

[30] Pfeiffer F, Bech M, Bunk O et al (2008) Hard-X-ray darkfield imaging using a grating interferometer. Nat Mater 7:134-137. https://doi.org/10.1038/nmat2096

[31] Mayo S, Endrizzi M (2018) X-ray phase contrast methods. In: Handbook of advanced non-destructive evaluation. Springer, Cham

[32] Momose A (2005) Recent advances in X-ray phase imaging. Jpn J Appl Phys Part 1 Regul Pap Short Notes Rev Pap 44:6355-6367. https://doi.org/10.1143/JJAP.44.6355

[33] Gusenbauer C, Leiss-Holzinger E, Senck S et al (2016) Characterization of medical and biological samples with a Talbot-Lau grating interferometer $\mu \mathrm{XCT}$ in comparison to reference methods. Case Stud Nondestruct Test Eval 6:30-38. https://doi.org/10.1016/j.csndt.2016.02.001
[34] Gusenbauer C, Reiter M, Plank B et al (2019) Porosity determination of carbon and glass fibre reinforced polymers using phase-contrast imaging. J Nondestruct Eval. https://d oi.org/10.1007/s10921-018-0529-6

[35] Glinz J, Senck S, Reiter M et al (2019) Improved visualization of polymer foams using Talbot-Lau grating interferometry to reduce metal artifacts. In: Proceedings of international symposium on Digital Industrial Radiology and Computed Tomography (DIR2019). Fürth, Germany, pp 1-9

[36] Schaff F, Prade F, Sharma Y et al (2017) Non-iterative directional dark-field tomography. Sci Rep 7:1-9. https://doi. org/10.1038/s41598-017-03307-6

[37] Jensen TH, Bech M, Zanette I et al (2010) Directional X-ray dark-field imaging of strongly ordered systems. Phys Rev B Condens Matter Mater Phys. https://doi.org/10.1103/PhysRe vB.82.214103

[38] Gromann LB, De Marco F, Willer K et al (2017) In-vivo $\mathrm{X}$-ray dark-field chest radiography of a pig. Sci Rep 7:1-7. h ttps://doi.org/10.1038/s41598-017-05101-w

[39] Yaroshenko A, Meinel FG, Bech M et al (2013) Pulmonary emphysema diagnosis with a preclinical small-animal x-ray dark-field scatter-contrast scanner. Radiology 269:427-433. https://doi.org/10.1148/radiol.13122413/-/DC1

[40] Arboleda C, Wang Z, Jefimovs K et al (2019) Towards clinical grating-interferometry mammography. Eur Radiol. h ttps://doi.org/10.1007/s00330-019-06362-x

[41] Scherer K, Braig E, Ehn S et al (2016) Improved diagnostics by assessing the micromorphology of breast calcifications via X-ray dark-field radiography. Sci Rep 6:1-11. https://doi. org/10.1038/srep36991

[42] Senck S, Scheerer M, Revol V et al (2018) Microcrack characterization in loaded CFRP laminates using quantitative two- and three-dimensional X-ray dark-field imaging. Compos Part A Appl Sci Manuf 115:206-214. https://doi. org/10.1016/j.compositesa.2018.09.023

[43] Senck S, Scheerer M, Revol V et al (2017) Non-destructive evaluation of defects in polymer matrix composites for aerospace applications using X-ray Talbot-Lau interferometry and micro CT. In: 58th AIAA/ASCE/AHS/ASC Struct Struct Dyn Mater Conf, pp 1-9. https://doi.org/10.2514/6. 2017-0355

[44] Amirkhanov A, Amirkhanov A, Salaberger D et al (2016) Visual analysis of defects in glass fiber reinforced polymers for 4DCT interrupted in situ tests. Comput Graph Forum 35:201-210. https://doi.org/10.1111/cgf.12896

[45] Senck S, Salaberger D, Gusenbauer C et al (2016) TalbotLau grating interferometer XCT for the quantitative characterization of damage in polymers after impact and static tensile testing. In: 19th World Conference on Non-Destructive Testing, WCNDT 2016, pp 1-8 
[46] Prade F, Schaff F, Senck S et al (2017) Nondestructive characterization of fiber orientation in short fiber reinforced polymer composites with X-ray vector radiography. NDT E Int 86:65-72. https://doi.org/10.1016/j.ndteint.2016.11.013

[47] Revol V, Plank B, Kaufmann R et al (2013) Laminate fibre structure characterisation of carbon fibre-reinforced polymers by X-ray scatter dark field imaging with a grating interferometer. NDT E Int 58:64-71. https://doi.org/10.1016/ j.ndteint.2013.04.012

[48] Bayer F, Zabler S, Brendel C et al (2013) Projection angle dependence in grating-based X-ray dark-field imaging of ordered structures. Opt Express 21:19922. https://doi.org/10. 1364/oe.21.019922

[49] Glinz J, Thor M, Ayalur-Karunakaran S et al (2021) Inspection of fiber waviness in carbon fiber laminates by Talbot-Lau X-ray grating interferometry. In: AIAA Scitech 2021 Forum. American Institute of Aeronautics and Astronautics, $\mathrm{p} 8$

[50] Chabior M, Schuster M, Goldammer M et al (2012) Influence of the grating profiles on the image quality in gratingbased X-ray imaging. Nucl Instrum Methods Phys Res Sect A Accel Spectrom Detect Assoc Equip 683:71-77. https://d oi.org/10.1016/j.nima.2012.04.068

[51] Hollowell AE, Arrington CL, Finnegan P et al (2019) Double sided grating fabrication for high energy X-ray phase contrast imaging. Mater Sci Semicond Process 92:86-90. h ttps://doi.org/10.1016/j.mssp.2018.04.016

[52] Dittmann J, Balles A, Zabler S (2018) Optimization based evaluation of grating interferometric phase stepping series and analysis of mechanical setup instabilities. J Imaging 4:1-18. https://doi.org/10.3390/jimaging4060077

[53] Rong F, Liang Y, Xu W et al (2018) X-ray phase contrast imaging by talbot-lau interferometer without phase-stepping device. IEEE Photonics Technol Lett 30:1795-1798. http s://doi.org/10.1109/LPT.2018.2869423

[54] Hahn D, Thibault P, Fehringer A et al (2015) Statistical iterative reconstruction algorithm for X-ray phase-contrast CT. Sci Rep 5:1-8. https://doi.org/10.1038/srep10452

[55] Birnbacher L, Viermetz M, Noichl W et al (2018) Tilted grating phase-contrast computed tomography using statistical iterative reconstruction. Sci Rep 8:1-8. https://doi.org/10. 1038/s41598-018-25075-7

[56] Fröhler B, da Cunha Melo L, Weissenböck J et al (2019) Tools for the analysis of datasets from X-ray computed tomography based on Talbot-Lau grating interferometry. In 9th Conf Ind Comput Tomogr (iCT 2019), 13-15 Febr 2019, Padova, Italy, paper 52

[57] Gusenbauer C, Reiter M, Plank B et al (2017) Multi-modal Talbot-Lau grating interferometer XCT data for the characterization of carbon fibre reinforced polymers with metal components. In: Proceedings of the 7 th conference on industrial computed tomography, pp 1-9

[58] Kastner J, Gusenbauer C, Plank B et al (2019) Challenges for grating interferometer X-ray computed tomography for practical applications in industry. Insight Non-Destruct Test Cond Monit. https://doi.org/10.1784/insi.2019.61.3.149

[59] Endrizzi M (2018) X-ray phase-contrast imaging. Nucl Instrum Methods Phys Res Sect A Accel Spectrom Detect Assoc Equip 878:88-98. https://doi.org/10.1016/j.nima.201 7.07 .036

[60] Olivo A, Gkoumas S, Endrizzi M et al (2013) Low-dose phase contrast mammography with conventional X-ray sources. Med Phys. https://doi.org/10.1118/1.4817480

[61] Tavakoli-Taba S, Baran P, Lewis S et al (2019) Toward improving breast cancer imaging: radiological assessment of propagation-based phase-contrast CT technology. Acad Radiol 26:e79-e89. https://doi.org/10.1016/j.acra.2018.07. 008

[62] Wang H, Kashyap Y, Cai B, Sawhney K (2016) High energy $\mathrm{X}$-ray phase and dark-field imaging using a random absorption mask. Sci Rep 6:1-7. https://doi.org/10.1038/sre p30581

[63] Endrizzi M, Murat BIS, Fromme P, Olivo A (2015) Edgeillumination X-ray dark-field imaging for visualising defects in composite structures. Compos Struct 134:895-899. http s://doi.org/10.1016/j.compstruct.2015.08.072

[64] Revol V, Jerjen I, Kottler C et al (2011) Sub-pixel porosity revealed by X-ray scatter dark field imaging. J Appl Phys. h ttps://doi.org/10.1063/1.3624592

[65] Gresil M, Revol V, Kitsianos K et al (2017) EVITA Project: comparison between traditional non-destructive techniques and phase contrast X-ray imaging applied to aerospace carbon fibre reinforced polymer. Appl Compos Mater 24:513-524. https://doi.org/10.1007/s10443-016-9540-1

[66] Talbot HF (1836) LXXVI. Facts relating to optical science. No. IV London, Edinburgh, Dublin. Philos Mag J Sci 9:401-407. https://doi.org/10.1080/14786443608649032

[67] Momose A, Kawamoto S, Koyama I et al (2003) Demonstration of x-ray Talbot interferometry. Jpn J Appl Phys 42(Part 2):L866-L868. https://doi.org/10.1143/jjap.42.1866

[68] Willner M, Herzen J, Grandl S et al (2014) Quantitative breast tissue characterization using grating-based $\mathrm{X}$-ray phase-contrast imaging. Phys Med Biol 59:1557-1571. htt ps://doi.org/10.1088/0031-9155/59/7/1557

[69] Scherer K, Braig E, Willer K et al (2015) Non-invasive differentiation of kidney stone types using X-ray dark-field radiography. Sci Rep 5:1-7. https://doi.org/10.1038/sre p09527 
[70] Jensen TH, Bech M, Bunk O et al (2010) Directional X-ray dark-field imaging. Phys Med Biol. https://doi.org/10.1088/ 0031-9155/55/12/004

[71] Zanette I, Weitkamp T, Lang S et al (2011) Quantitative phase and absorption tomography with an X-ray grating interferometer and synchrotron radiation. Phys Status Solidi Appl Mater Sci 208:2526-2532. https://doi.org/10.1002/pss a.201184276
[72] Loendersloot R, Lomov SV, Akkerman R, Verpoest I (2006) Carbon composites based on multiaxial multiply stitched preforms. Part V: geometry of sheared biaxial fabrics. Compos Part A Appl Sci Manuf 37:103-113. https://doi.org/ 10.1016/j.compositesa.2005.04.013

Publisher's Note Springer Nature remains neutral with regard to jurisdictional claims in published maps and institutional affiliations. 